\title{
NOTE ON THE DETECTION OF COTTON-SEED OIL IN LARD.
}

\author{
By E. J. Bevan.
}

Read at the Meeting, February 7, 1894.

Some time ago I had occasion to examine a sample of lard for cotton-seed oil. This lard, which $I$ knew to be genuine, gave the silver reaction. On finding this, the first thing I did was to make a new silver solution, but I found that the sample gave the reaction with all the solutions tried. It so happened that the bottle containing this lard had been long exposed to the air and the fumes of the laboratory. This gave me a clue to the matter. By scraping off the top portion, and taking a part of what lay underneath to which the air had not penetrated, I obtained no silver reaction whatever. I then took a sample of bladder-lard, and I observed the same phenomena. The portion immediately under the skin gave the silver reaction readily, whereas a portion taken right inside the mass in the bladder gave no reaction whatever. The fact that the lard underneath the skin gave the reaction showed, of course, that it was not due to the presence of any mechanically-deposited dirt. Then I tried exposing the lard in a still room in flat dishes. I found that after about a week's exposure the lard gave the silver reaction quite strongly. I can come to no other conclusion than that the effect observed was due to oxidation. I should say that I also exposed the lard to the fumes of various substances without afterwards obtaining any silver reaction whatever. I passed air for two or three days through some melted lard, and I found that with the lard so treated the reaction was intense. I estimated the amount of iodine absorption, the free acid, and one or two other things, and found no differences whatever, so that evidently the substance which is formed must be very minute in amount, but there is quite enough to mislead one, and give one the impression that cotton-oil is really present.

I notice that in the January number of the journal of the Chemical Society there appears an abstract of a "Note on the Reducing Action of Rancid Fat." It is stated by the author of that note that butter which has become rancid gives the cottonseed oil reaction in a marked manner, and he also goes on to say that he considers the reaction to be due to the presence of sulphur compounds in lard, like those in certain vegetable oils. I do not think that this is true. It is known that lards do not contain sulphur compound. I cannot see that the effect is due to rancidity.

Mr. Chattaway said that it seemed to him strange that if the presence of free acid was in any way the cause of what Mr. Bevan had demonstrated, one should not get the reaction with the fatty acids themselves. He had very frequently tested fatty acids, and obtained no silver reaction.

Mr. Otto Hehner said that rancidity was not solely due to liberation of fatty acids, but was largely attributable to oxidation. Rancid fats, when saponified with alcoholic potash, gave a more or less yellow solution, similar to that produced when alkalies acted upon aldehydes; his impression was that rancidity was accompanied by the formation of aldehydic bodies. Mr. Mariani had pointed out that rancidity might cause butter-fat to yield a reaction with silver nitrate similar to the Becchi reaction. He (Mr. Hehner) advised members not to put too much trust in the cotton 
seed oil reaction when applied to butter, as he had found that when cows were fed with large quantities of cotton-seed cake, the butter obtained from the milk of cows so fed would not unfrequently give the reaction for cotton-seed oil.

$\mathrm{He}$ would like to elicit from members some information concerning lard. A few years ago, when cotton-seed oil was frequently present in lard, the iodine absorption was largely relied upon in lard-testing. Lately, cotton-seed oil was but very rarely met with in lard, yet the iodine absorption had, if anything, increased, although beefstearin, which had a very low iodine number, was often present. Hence the presence of some oil other than cotton-seed or lard oil must be suspected.

Mr. Cassal drew Mr. Bevan's attention to the fact that according to the abstract of Mr. Mariani's paper in the journal of the Chemical Society he appeared to have stated that he had shown lard and animal fats to contain sulphur compounds, and to have based that statement upon his having obtained the silver reaction with these fats, and upon his having found the deposit to consist partly of sulphide of silver.

Mr. Richmond, with respect to the presence of sulphur in the fat of animals pointed out that when he was in Egypt he examined the milk of the gamoose, and in the fat there was 0.05 per cent. of sulphur, and it gave, after saponification, a very strong reaction with both silver and lead paper. He thought it possible that, as sulphur was present in the fat of one animal, it might also be found in that of others.

Mr. Bevan said that he had only read the passage casually, but it seemed to him that there was not sufficient evidence upon which Mariani could base his statement. 